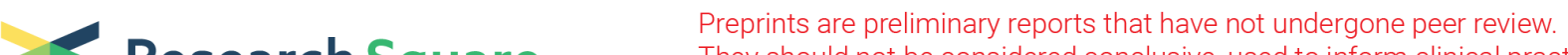 $\begin{array}{ll}\text { Research Square } & \text { They should not be considered conclusive, used to inform clinical practice, } \\ \text { or referenced by the media as validated information. }\end{array}$ \\ Guidelines Translation for Distress Management in Cancer Patients Based on CAN-IMPLEMENT: Implementation Part
}

\section{Liang Fu}

Fudan University/Affiliated Jinhua Hospital, Zhejiang University School of Medicine

\section{Xiaoju Zhang}

Fudan University Shanghai Cancer Center

Yan Hu ( $D$ huyan@fudan.edu.cn )

Fudan University https://orcid.org/0000-0001-6506-0694

\section{Zhenqi Lu}

Fudan University Shanghai Cancer Center

\section{Yang Yang}

Fudan University Shanghai Cancer Center

\section{Mingzhu Huang}

Fudan University Shanghai Cancer Center

\section{Yuanyuan Li}

Zhongshan Hospital Affiliated to Fudan University

\section{Fuzhong Zhu}

Fudan University Shanghai Cancer Center

\section{Yang Wang}

Fudan University Shanghai Cancer Center

\section{Zhe Huang}

Fudan University Shanghai Cancer Center

\section{Research}

Keywords: Clinical Practice Guidelines, Implementation, Translation, Cancer, Distress Management

Posted Date: August 17th, 2020

DOI: https://doi.org/10.21203/rs.3.rs-53485/v1

License: (c) (1) This work is licensed under a Creative Commons Attribution 4.0 International License. Read Full License 


\section{Abstract}

Background: Stomach cancer patients receiving chemotherapy suffered severe distress. This study aimed to align the Cancer-related Distress Management Guidelines into clinical practice among stomach cancer patients receiving chemotherapy, and to monitor the implementation process of Cancer-related Distress Management Guidelines, evaluate the effects of guidelines implementation, and maintain the guidelines implementation in clinical practice.

Methods: A Guideline Adaptation and Implementation Planning Resource (CAN-IMPLEMENT) was used as the research framework, which include three phases. Here the Implementation Part (Phase 2 and Phase 3) was reported: alignment of Cancer-related Distress Management Guidelines in clinical practice among stomach cancer patients receiving chemotherapy, and process monitoring and outcome evaluation of Cancer-related Distress Management Guidelines.

Results: After the guidelines implementation, the formal audit criteria, working pathways, assessment tools, multidisciplinary panels, training manual for healthcare professionals, education and handbook for patients and their caregivers of distress management were developed on institutional level, as well as the related assessment tools and record forms. The completion rate of distress management record was increased from $0.0 \%$ to $97.9 \%(P<0.001)$. The compliance of most items in the audit checklist for medical staff's distress management were improved, from $57.1 \%$ to $100.0 \%(P<0.001)$. The distress positive rate of stomach cancer patients receiving chemotherapy was decreased from $22.7 \%$ to $9.3 \%(P<0.05)$, and the distress scores were declined from $2(0-9)$ to $0(0-7)(P<0.001)$.

Conclusions: The completion rate of distress management records increased significantly after guidelines implementation, revealing the process quality control of the distress management practice was good. At the institutional level, this guidelines implementation promoted the establishment of distress management system. To healthcare professionals, the guidelines implementation improved the distress management compliance. For stomach cancer patients receiving chemotherapy, distress management practices can effectively improve the distress of stomach cancer patients receiving chemotherapy.

\section{Contributions To The Literature}

- The "Outcomes" of PIPOH health problem could be essential and underscored indicators for effect evaluation of guidelines application.

- The outcome indicators for the gap analysis should be consistent with the indicators for process monitoring and outcome evaluation of guidelines implementation.

- The intervention strategies deriving from barriers and facilitators analysis must be definitely distinguished from "Interventions" of PIPOH health problem, as well as the corresponding study participants and outcome variables in implementation stage. 
- The guidelines implementation was feasible in low and middle income countries based on CANIMPLEMENT and guided by the Knowledge-to-Action Framework.

\section{Background}

Stomach cancer is one of the top 10 cancer types worldwide. The new cases of stomach cancer was over $1,000,000$ and the deaths was about 783,000 in 2018, making it the fifth most frequently diagnosed cancer and the third leading cause of cancer death [1]. In China, there were approximately 679,100 new cases and 498,000 deaths of stomach cancer in 2015, ranking second after lung cancer among all cancer types [2]. Hong et al. reported that the prevalence of clinically significant preoperative psychological distress was $76.97 \%$ in Chinese patients with newly diagnosed stomach cancer ${ }^{3}$. In addition, patients with clinically psychological distress were more likely to have poor quality of life and to demonstrate negative coping styles [3]. In the research site, the research team found that most stomach cancer patients have a low education level and a high age [4]. These patients are not good at expressing emotions, and their psychological care needs are easily overlooked. At the same time, all stomach cancer patients in the research site were undergoing chemotherapy or preparing for chemotherapy. Therefore, it was decided to recruit stomach cancer patients receiving chemotherapy as the research object of the guideline implementation after group discussion.

The guidelines implementation is a process of changing practice in health care while utilizing the best level of evidence that is available in the published literature [5]. As the critical link to put evidence into practice successfully, guidelines implementation is usually full of difficult challenges $[6,7]$. Fischer et al. indicated that the barriers to guideline implementation can be differentiated into personal factors, guideline-related factors, and external factors [8]. Accordingly, the corresponding strategies were identified, including dissemination, education and training, social interaction, decision support systems and standing orders [8]. Cheng et al. demonstrated the main barriers to evidence-based nursing implementation in China were lack of knowledge and skills for nurses, following by lack of protocol and heavy workload for system [9]. Lack of knowledge Another study conducted in China showed higher frequency and higher ranking of barriers for the guidelines implementation all converged on 'lack of access', 'less convenient', 'lack of applicability' and 'lack of evidence from Chinese sample', and higher frequency and higher ranking of enablers converged on 'Short formats presentation', 'Utilisation of various media', 'Information visualisation' and 'Linking to patient electronic medical records' [10].

This guidelines implementation project was closely collaborated among university and hospitals. To ensure the authority and resources required for the guidelines implementation, a multidisciplinary panel of guidelines implementation was developed. The members of the panel included hospital decision makers, department managers, guidelines adaptors, frontline medical staff, cancer patients, university researchers, etc., and can provide support in policies, resources, practice, management, etc. The participation of some core members of the guidelines adaptation panel can better ensure the consistency and continuity of guidelines adaptation and guidelines implementation. In addition, professionals in clinical practice situations are always faced with complex and heavy health care work. Researchers need 
to monitor the guidelines application process to understand the practice of guidelines' users following the recommendations, carry out the guidelines evaluation to clarify the effectiveness of the guidelines application, and maintain the guidelines application to regularize the guidelines' recommendations in the current practice situation.

\section{Aim}

Aims of this study was to carry out guidelines adaptation and implementation for distress management in cancer patients, which was based on CAN-IMPLEMENT and guided by the Knowledge-to-Action Framework. The adaptation part was reported in another paper. This section focused on implementation process. The Implementation Part (Phase 2 and Phase 3) was to align the Cancer-related Distress Management Guidelines into clinical practice among stomach cancer patients receiving chemotherapy, and to monitor the implementation process of Cancer-related Distress Management Guidelines, evaluate the effects of guidelines implementation, and maintain the guidelines implementation in clinical practice. The specific objectives in Implementation Part were as follows: (1) To explore the gap between the current distress management and recommendations in the adapted guidelines; (2) To analyzing gaps, assessing barriers and supports of guidelines implementation from guidelines, users and practice context, and developing appropriate solutions; (3) To monitor the process and evaluate the outcome of this guidelines implementation; (4) To regularize the distress management among stomach cancer patients receiving chemotherapy.

\section{Methods}

Ethics approval for this study was obtained from School of Nursing XX University (IRB\#2017-9-3) and XX University XX Cancer Centre (1710177-23). From May 2017 to June 2019, the study 'Guidelines Adaptation and Implementation for Distress Management in Cancer Patients' was conducted in School of Nursing, XX University and three medical oncology units, XX Cancer Center, China. The main contents of the above study were translating relevant guidelines on distress management into clinical practice, which was based on CAN-IMPLEMENT and guided by the Knowledge-to-Action Framework. The translation and application of CAN-IMPLEMENT in China was authorized by the principal investigator of CANIMPLEMENT project.

According to CAN-IMPLEMENT, this study consisted of three phases: (1) integrating relevant clinical practice guidelines on the distress management in cancer patients to form the Cancer-related Distress Management Guidelines; (2) aligning the Cancer-related Distress Management Guidelines into clinical practice among stomach cancer patients receiving chemotherapy; (3) monitoring, evaluating and maintaining the implementation of Cancer-related Distress Management Guidelines in clinical practice. Here the Implementation Part (Phase 2 and Phase 3) was reported.

\section{Phase 2 Solution Building: Guidelines Alignment}


Step 6 Align Knowledge to Local Context: A multidisciplinary panel of guidelines implementation was set up. The recommendations in the adapted guidelines were translated to practical audit criteria considering the local practice contexts and the specific responsibilities of the professionals. A guidelines implementation work plan was developed by the multidisciplinary panel of guidelines implementation.

From September 2017 to June 2018, a cross-sectional study was conducted to describe and analyze the stomach cancer patients' distress and the gap between the current distress management and guidelines' recommendations. The self-designed distress management record in cancer patients, the self-designed audit checklist for medical institution's distress management, the self-designed audit checklist for medical staff's distress management, the Distress Thermometer (DT) [11] and the Hospital Anxiety and Depression Scale (HADS) [12] were used as instruments. The participants were a medical oncology unit, eight doctors, 20 nurses, eight mental health professionals, two social workers, four palliative care staff and 141 stomach cancer patients receiving chemotherapy.

Step 7 Assess Barriers and Facilitators to Knowledge Use / Step 8 Select and Tailor Implementation Interventions: Eight experts (two supervisor nurses and two nurse practitioners of oncology nursing, a supervisor nurse of palliative care, a physician of psychological medicine, a social worker, a nurse of psychological care) were invited to assess the barriers and supports of guidelines implementation, and develop feasible solutions by using the expert meeting method from innovation, adopters and practice environment.

\section{Phase 3 Implementation, Evaluation and Sustainability: Guidelines Application and Evaluation}

Step 9 Monitor Knowledge Use / Step 10 Evaluate Outcomes: A historical controlled trial was conducted with the same instruments in Step 6 between July 2018 and December 2018. The subjects included a medical oncology unit, eight doctors, 20 nurses, eight mental health professionals, two social workers, four palliative care staff and 193 stomach cancer patients receiving chemotherapy. In addition to the stomach cancer patients, the subjects were same with the participants in the gap analyses.

Step 11 Nuture Change and Sustain Knowledge Use: From January to March 2019, the implementation of Cancer-related Distress Management Guidelines was sustained by assessing barriers and facilitators to knowledge use, selecting and tailoring implementation interventions, monitoring process and evaluating outcomes again. For monitoring process and evaluating outcomes, another historical controlled trial was performed including a medical oncology unit, eight doctors, 20 nurses, eight mental health professionals, two social workers, four palliative care staff and 30 stomach cancer patients receiving chemotherapy. In addition to the stomach cancer patients, the subjects were same with the participants in the gap analyses. The instruments were same with these used in Step 6.

\section{Results}

\section{Phase 2 Solution Building: Guidelines Alignment}


The multidisciplinary panel of guidelines implementation included a professor and an associate professor skilled with evidence-based practice methodologies, a chief physician of psychological medicine, a chief physician of palliative care, a chief physician, an associate chief physician and an attending doctor of oncology, a professor, an associate professor, three supervisor nurses, two nurse practitioners and two nurses of oncology nursing, an associate professor of psychological care, two social workers, a doctoral candidate and a postgraduate student of nursing science.

Ten translated practical audit criteria were developed based on the extracted recommendations from the adapted guidelines. Table 1. The distress management clinical pathways were also developed based on the translated practical audit criteria. Figure 1. The work plan of guidelines implementation were presented as a protocol for a historical controlled trial. The contents of work plan included the following parts: design, participant, inclusion criteria, sample size, research site, intervention, instruments, data collection, analyses and so on. The interventions were the practical audit criteria based on the recommendations in the adapted guidelines.

Before the guidelines implementation, there was no formal audit criteria, working pathways, assessment tools, multidisciplinary panels, training manual for healthcare professionals, education and handbook for patients and their caregivers of distress management on institutional level, as well as the related assessment tools and record forms. Therefore, the completion rate of distress management record was $0.0 \%$ at baseline. The compliance of each item on the audit checklist for medical staff's distress management in cancer patients were all $0.0 \%$. Table 2 . The distress positive rate of stomach cancer patients receiving chemotherapy (DT $\geq 4$ ) was $22.7 \%$, and the distress score was $2(0-9)$. Table 3 and Table 4. The problem report rates of stomach cancer patients receiving chemotherapy with moderate to severe distress were $0.0 \%$ to $75.0 \%$. The positive rates of anxiety and depression were both $40.0 \%$.

Step 7 Assess Barriers and Facilitators to Knowledge Use / Step 8 Select and Tailor Implementation Interventions

Six barriers and six supports of the guidelines implementation were identified from the guidelines, the adopters and the practice environment. Ten corresponding solutions were developed too. Figure 2.

\section{Phase 3 Implementation, Evaluation and Sustainability: Guidelines Application and Evaluation}

Step 9 Monitor Knowledge Use / Step 10 Evaluate Outcomes

After the guidelines implementation, the formal audit criteria, working pathways, assessment tools, multidisciplinary panels, training manual for healthcare professionals, education and handbook for patients and their caregivers of distress management on institutional level were developed, as well as the related assessment tools and record forms. Except for the body mass index, there was no statistically significant difference on the general conditions of the two groups of patients before and after the guidelines implementation ( $P>0.05$ ). Table 5. The completion rate of distress management record was 
increased from $0.0 \%$ to $97.9 \%(P<0.001)$. The compliance of most items on the audit checklist for medical staff's distress management were improved, from $57.1 \%$ to $100.0 \%(P<0.001)$. Table 2 . The distress positive rate of stomach cancer patients receiving chemotherapy was decreased from $22.7 \%$ to 9.3\% $(P<0.05)$, and the distress scores were declined from $2(0-9)$ to $0(0-7)(P<0.001)$. Table 3 and Table 4. The problem reporting rates of stomach cancer patients receiving chemotherapy with moderate to severe distress were slightly lower, from $0.0 \%$ to $61.1 \%(P>0.05)$. The positive rates of anxiety and depression were both slightly increased to $64.7 \%$ ( $P>0.05)$.

Step 11 Nuture Change and Sustain Knowledge Use

The results of the guidelines implementation maintenance were similar to those during the guidelines implementation period. The formal audit criteria, working pathways, assessment tools, multidisciplinary panels, training manual for healthcare professionals, education and handbook for patients and their caregivers of distress management on institutional level were maintained, as well as the distress management record. When compared to the results of gap analyses, the compliance of most items in the audit checklist for medical staff's distress management were improved to $89.7 \%-100.0 \%(P<0.001)$, the distress positive rate of stomach cancer patients receiving chemotherapy was decreased to $3.3 \%$ $(P<0.001)$, and the distress scores were sustained at $0.5(0-5)(P<0.001)$.

\section{Discussion}

The members in multidisciplinary panel of guidelines implementation included different roles, such as hospital decision makers, department managers, frontline medical staff, patients, and university researchers. They can provide support in terms of policies, resources, practice, and management. Some core members of the guidelines adaptation panel were also members of the guidelines implementation panel, which can better ensure the consistency and continuity of the guidelines translation, so as to smoothly advance the guidelines implementation. The work plan of guidelines implementation was formulated by coordinating resources related to nursing, psychological medicine, social work, and medical treatment under the leading of the guidelines implementation panel. In the gap analyses, the difference between distress management practice in the research site and recommendations in the adapted guidelines was quite big. There was no distress management system at institutional level before the guidelines implementation, and healthcare professionals almost do not provide any services on distress management for cancer patients. However, the distress status of stomach cancer patients receiving chemotherapy was not optimistic. Distress has large negative impact on patients' quality of life [3]. Therefore, it is necessary to carry out distress management $[13,14,15]$. The barriers and supports of this guidelines implementation were identified from the aspects of guidelines, the adopters and the practice environment [16]. Grifford and her colleagues reported that barriers included lack of evidence, inadequate knowledge in evidence-based practice, and patients' inability to understand new evidence, while leadership support and network information services were factors that promote evidence-based practice [17]. The results in this study were similar to results of her study. Meanwhile, the solutions corresponding to the above barriers and supports were formulated, including education and training, 
communication and exchange, review and feedback, patient-related measures, organization-level intervention and so on.

The completion rate of distress management records increased significantly during the guidelines implementation, revealing the process quality control of the distress management practice was good. At the institutional level, this guidelines implementation promoted the establishment of distress management system. The results of this study indicate that the research site approved the Cancer-related Distress Management Guidelines, formed the specific and operable clinical pathways, and formulated related assessment tools and record forms. At the same time, a multidisciplinary team for distress management in cancer patients had been established, a standardized training and education project for medical staff and patients had been formed, training manual had been produced for medical staff training, and educational handbook had been sent to patients and their caregivers. To the healthcare professionals, the guidelines implementation improved the distress management compliance according to the recommendations in the adapted guidelines. The high compliance demonstrated the overall maturity of distress management in cancer patients and trouble-free operation of the multidisciplinary team. Patients who need distress management can receive distress management services in a timely, convenient and effective manner. In terms of stomach cancer patients receiving chemotherapy, the positive rate and score of distress decreased significantly after the guidelines implementation, indicating that distress management practices can effectively improve the distress of stomach cancer patients receiving chemotherapy. Previous studies also showed that distress management can reduce distress in cancer patients. Millegan et al. reported that the use of iPads during chemotherapy is a potentially effective way to introduce meditation as a stress management tool for people with cancer [18].

This study has the following limitations. First, barriers and facilitators to knowledge use were assessed using expert meeting method. The questionnaire survey may be more appropriate. Second, the study design of guidelines evaluation was a historical controlled trial. It is recommended to use stepped wedge trail design in future studies. Third, only stomach cancer patients receiving chemotherapy were included in the guidelines implementation. Thus, the results need to be further verified in patients with other types of tumors before being popularized.

\section{Conclusion}

The gap between distress management practice in the research site and the guideline recommendations was quite different. Meanwhile, the guidelines implementation barriers and supports were identified, feasible solutions were developed. The process quality control of the distress management practice in cancer patients was good. The evidence translation project can facilitate the establishment of distress management system and resources, promote the medical staff to improve the distress management compliance, and reduce the level of distress in cancer patients. The maintenance of the guidelines implementation can sustain the clinical translation effects. Thus, guidelines implementation was feasible in low and middle income countries based on CAN-IMPLEMENT and guided by the Knowledge-to-Action Framework. 


\section{Abbreviations}

CANIMPLEMENT

A Guideline Adaptation and Implementation Planning Resource; DT:Distress Thermometer; HADS:Hospital Anxiety and Depression Scale

\section{Declarations}

\section{Availability of data and materials}

The datasets used and/or analysed during the current study are available from the corresponding author on reasonable request.

\section{Ethics approval and consent to participate}

Ethical approval was obtained via School of Nursing Fudan University (IRB\#2017-9-3) and Fudan University Shanghai Cancer Centre (1710177-23).

\section{Consent for publication}

Not applicable.

\section{Competing Interests}

The authors declare they have no competing interests.

\section{Funding}

This study was funded by Fudan-Fuxing Nursing Research Funds (No. FNF201701) from Fudan University, Shanghai, China. No conflicts of interest exist in the study. The sponsor did not participate in the study design, data collection, interpretation of results, or presentation of the information.

\section{Authors' contributions}

YH and $Z L$ mainly designed this research plan. $L F, Y Y, X Z$ and $Y W$ mainly completed the guidelines adaptation. $L F, Y Y, X Z, M H, Y L, F Z, Y W$ and $Z H$ are mainly responsible for the guidelines implementation. All authors read and approved the final manuscript.

\section{Acknowledgments}


The authors' special thanks go to Professor Margaret B. Harrison for her authorization of A Guideline Adaptation and Implementation Planning Resource (CAN-IMPLEMENT). The authors wish to thank master students from School of Nursing, Fudan University for the searching, screening, assessment, selection and drafting in the guidelines adaptation. The authors express their gratitude to the professors, administrators and staffs from Joanna Briggs Institute, Department of Psychological Medicine, Zhongshan Hospital Affiliated to Fudan University and Department of Oncology, Department of Social Work, Department of Integrated Therapy, Department of Nursing, Fudan University Shanghai Cancer Center for their participation in the peer review of the adapted guidelines and the routine distress management during the guidelines implementation. Finally, they wish to express their gratitude to all the patients who participated in this study.

\section{References}

1. Freddie B. Jacques, et al. Global cancer statistics 2018: GLOBOCAN estimates of incidence and mortality worldwide for 36 cancers in 185 countries. Cancer J Clin. 2018;68:394-424.

2. Chen W, Zheng R, Baade PD, et al. Cancer statistics in China, 2015. CA Cancer J Clin. 2016;66:11532.

3. Hong J, Wei Z, Wang W. Preoperative psychological distress, coping and quality of life in Chinese patients with newly diagnosed gastric cancer. J Clin Nurs. 2015;24:2439-47.

4. Fu L, Hu Y, Lu Z, et al. Validation of the Simplified Chinese Version of the Memorial Symptom Assessment Scale-Short Form Among Cancer Patients. J Pain Symptom Manage. 2018;56:113-21.

5. Beauchemin M, Cohn E, Shelton RC. Implementation of Clinical Practice Guidelines in the Health Care Setting: A Concept Analysis. ANS Adv Nurs Sci. 2019;42:307-24.

6. Rapport F, Clay-Williams R, Churruca K, et al. The struggle of translating science into action: Foundational concepts of implementation science. J Eval Clin Pract. 2018;24:117-26.

7. Barreto J. Implementation of clinical guidelines: a knowledge translation challenge. Rev Bras Epidemiol. 2018;21:e180022.

8. Fischer F, Lange K, Klose K, et al. Barriers and Strategies in Guideline Implementation-A Scoping Review. Healthcare (Basel). 2016;4.

9. Cheng L, Feng S, Hu Y. Evidence-based nursing implementation in Mainland China: A scoping review. Nurs Outlook. 2017;65:27-35.

10. Jin Y, Li Z, Han F, et al. Barriers and enablers for the implementation of clinical practice guidelines in China: a mixed-method study. Bmj Open. 2019;9:e26328.

11. Tang LL, Zhang YN, Pang Y, et al. Validation and reliability of distress thermometer in chinese cancer patients. Chin J Cancer Res. 2011;23:54-8.

12. Li Q, Lin Y, Hu C, et al. The Chinese version of hospital anxiety and depression scale: Psychometric properties in Chinese cancer patients and their family caregivers. Eur J Oncol Nurs. 2016;25:16-23. 
13. Carlson LE, Zelinski EL, Toivonen KI, et al. Prevalence of psychosocial distress in cancer patients across 55 North American cancer centers. J Psychosoc Oncol. 2019;37:5-21.

14. Stonelake-French $\mathrm{H}$, Moos BE, Brueggen CM, et al. Understanding Distress in the Hospital: A Qualitative Study Examining Adults With Cancer. Oncol Nurs Forum. 2018;45:206-16.

15. Hedden L, Wassersug R, Mahovlich S, et al. Evaluating an educational intervention to alleviate distress amongst men with newly diagnosed prostate cancer and their partners. Bju Int. 2017;120:E21-9.

16. Harrison MB, van den Hoek J, for the Canadian Guideline Adaptation Study Group. CAN-IMPLEMENT: a guideline adaptation and implementation planning resource. Ontario: Queen's University School of Nursing and Canadian Partnership Against Cancer; 2012.

17. Gifford W, Zhang Q, Chen S, et al. When east meets west: a qualitative study of barriers and facilitators to evidence-based practice in Hunan China. BMC Nursing. 2018;17:26.

18. Millegan J, Manschot B, Dispenzieri M, et al. Leveraging iPads to introduce meditation and reduce distress among cancer patients undergoing chemotherapy: a promising approach. Support Care Cancer. 2015;23:3393-4.

\section{Tables}

Table 1 The recommendations in the adapted guidelines and the corresponding practical criteria 
Recommendations

Recommendation 1: All patients should be assessed prior to clinical visits using the Distress Thermometer, and immediate screenings should be provided during the vulnerable period.

Recommendation 2: If the patient's distress is mild (thermometer score $<4$ ), the primary oncology team should assess the possible distress related symptoms of the patient.

Recommendation 3: According to the assessment results of possible distress related symptoms, the primary oncology team manages the symptoms associated with the patient's distress.

Recommendation 4: After the primary oncology team manages the symptoms associated with the patient's distress, the Distress Thermometer is used again for followup screening.

Recommendation 5: If the patient's distress is moderate or severe (thermometer score $\geq 4$ ), further clinical evaluations should be provided by oncology team, including clinical interviews, anxiety/depression assessment, etc.

Recommendation 6: According to the results of further clinical evaluations, it is recommended to refer patients, and mental health professionals provide psychoeducation for patients in need.

Recommendation 7: According to the results of further clinical evaluations, it is recommended to refer patients, and mental health professionals provide cognitive behavioral therapy for patients in need.

Recommendation 8: According to the results of further clinical evaluations, it is recommended to refer patients, and mental health professionals provide supportive psychotherapy for patients in need.

Recommendation 9: According to the results of further clinical evaluations, it is recommended to refer patients, and mental health professionals provide family and couples therapy for patients in need.

Recommendation 10: According to the results of further clinical evaluations, it is recommended to refer patients, and social workers provide support and counseling to patients in need.

Recommendation 11: According to the results of further clinical evaluations, it is recommended to refer patients, and life meaning support staff provide life meaning care for patients in need.

Recommendation 12: According to the results of further clinical evaluations, it is recommended to refer patients, and medical staff provide palliative care for patients in need.

Recommendation 13: Patients who were referred or not referred to mental health professionals, social workers, life meaning support staff, medical staff were further screened using the Distress Thermometer.
Practical audit criteria

Practical audit criterion 1: Charge nurses screen and record distress for every patient using the Distress Thermometer when they visit the hospital, and patients' distress is immediately screened and recorded in vulnerable period.

Practical audit criterion 2: If the patient's distress is mild (thermometer score < 4), the charge nurse should use the distress standardization management record table to assess and record the possible distress related symptoms of the patient.

Practical audit criterion 3: According to the results of possible distress related symptoms, the charge nurse manage and record the symptoms associated with the patient's distress based on the distress management training manual, and refer to the professionals if necessary.

Practical audit criterion 4: After managing the symptoms associated with the patient's distress, the charge nurse should follow-up and record the patient's distress using the Distress Thermometer within 30 days on the patient's next admission or by telephone.

Practical audit criterion 5: If the patient's distress is moderate or severe (thermometer score $\geq 4$ ), the charge nurse should provide further clinical evaluation and records, including Problem List of the Distress Thermometer, the Hospital Anxiety and Depression Scale.

Practical audit criterion 6: According to the results of further clinical evaluations, the charge nurse advises the patient to refer, and the mental health professionals provide psychoeducation, supportive psychotherapy, cognitive behavioral therapy, family and couples therapy for patients in need.

Practical audit criterion 7: According to the results of further clinical evaluations, the charge nurse advises the patient to refer, and social workers provide support and counseling to patients in need.

Practical audit criterion 8: According to the results of further clinical evaluations, the charge nurse advises the patient to refer, and life meaning support staff provide life meaning care for patients in need.

Practical audit criterion 9: According to the results of further clinical evaluations, the charge nurse advises the patient to refer, and medical staff provide palliative care for patients in need.

Practical audit criterion 10: For patients who were referred or not referred to a professional for further treatment, the charge nurse should follow-up and record the patient's distress using the Distress Thermometer within 30 days on the patient's next admission or by telephone.

Table 2 The comparison on completion rate of distress management on the audit checklist for medical staff before and after the guidelines implementation 


\begin{tabular}{|c|c|c|c|c|c|c|c|c|}
\hline \multirow[t]{2}{*}{ Criteria } & \multirow[t]{2}{*}{$\mathrm{n}^{\mathrm{a}}$} & \multicolumn{2}{|c|}{ Before } & \multirow[t]{2}{*}{$\mathrm{n}^{\mathrm{a}}$} & \multicolumn{2}{|c|}{ After } & \multirow[t]{2}{*}{$c^{2}$} & \multirow[t]{2}{*}{$P$} \\
\hline & & $\mathbf{n}$ & $\%$ & & $\mathbf{n}$ & $\%$ & & \\
\hline 1 & 141 & 0 & 0.0 & 193 & 193 & 100.0 & 334.000 & $<0.001$ \\
\hline 2 & 109 & 0 & 0.0 & 175 & 175 & 100.0 & 284.000 & $<0.001$ \\
\hline 3 & 109 & 0 & 0.0 & 175 & 175 & 100.0 & 284.000 & $<0.001$ \\
\hline 4 & 109 & 0 & 0.0 & 175 & 100 & 57.1 & 96.137 & $<0.001$ \\
\hline 5 & 32 & 0 & 0.0 & 18 & 18 & 100.0 & 50.000 & $<0.001$ \\
\hline 6 & 29 & 0 & 0.0 & 17 & 12 & 70.6 & $-b$ & $<0.001$ \\
\hline 7 & 27 & 0 & 0.0 & 15 & 11 & 73.3 & $-b$ & $<0.001$ \\
\hline 8 & 0 & 0 & 0.0 & 0 & 0 & 0.0 & $-\mathrm{C}$ & - \\
\hline 9 & 31 & 0 & 0.0 & 17 & 17 & 100.0 & 48.000 & $<0.001$ \\
\hline 10 & 32 & 0 & 0.0 & 18 & 18 & 100.0 & 50.000 & $<0.001$ \\
\hline
\end{tabular}

a: Sample size varies depending on the assessment results of stomach cancer patients receiving chemotherapy; ${ }^{\text {b }}$ Fisher's exact test; ${ }^{c}$ : Chi-square test cannot be performed.

Table 3 The comparison on distress positive rate of stomach cancer patients receiving chemotherapy before and after the guidelines implementation

\begin{tabular}{lcccccc}
\hline $\begin{array}{r}\text { Periods } \\
\text { Positive Rates }\end{array}$ & \multicolumn{2}{c}{ Before $(\mathrm{n}=141)$} & \multicolumn{2}{c}{ After $(\mathrm{n}=193)$} & $c^{2}$ & $P$ \\
& $\mathrm{n}$ & $\%$ & $\mathrm{n}$ & $\%$ & & \\
\hline DT $\geq 4$ & 32 & 22.7 & 18 & 9.3 & 11.440 & 0.001 \\
& & & & & & \\
\hline
\end{tabular}

Table 4 The comparison on distress score of stomach cancer patients receiving chemotherapy before and after the guidelines implementation

\begin{tabular}{|c|c|c|c|c|c|c|c|c|}
\hline \multirow{2}{*}{$\begin{array}{l}\text { Periods } \\
\text { Scores }\end{array}$} & \multicolumn{3}{|c|}{ Before $(n=141)$} & \multicolumn{3}{|c|}{ After $(n=193)$} & \multirow[t]{2}{*}{$m$} & \multirow[t]{2}{*}{$P$} \\
\hline & Minimum & Maximum & Median & Minimum & Maximum & Median & & \\
\hline DT Scores & 0 & 9 & 2.00 & 0 & 7 & 0.00 & 10023.000 & $<0.001$ \\
\hline
\end{tabular}

Table 5 The comparison on general conditions of stomach cancer patients receiving chemotherapy before and after the guidelines implementation 


\begin{tabular}{|c|c|c|c|c|c|c|c|}
\hline \multirow[t]{2}{*}{ Items } & \multirow[t]{2}{*}{ Categories } & \multicolumn{2}{|c|}{ Before $(n=141)$} & \multicolumn{2}{|c|}{ After $(n=193)$} & \multirow[t]{2}{*}{$c^{2}$} & \multirow[t]{2}{*}{$P$} \\
\hline & & $\mathbf{n}$ & $\%$ & $\mathbf{n}$ & $\%$ & & \\
\hline \multirow[t]{2}{*}{ Gender } & Male & 96 & 68.1 & 114 & 59.1 & 2.838 & 0.092 \\
\hline & Female & 45 & 31.9 & 79 & 40.9 & & \\
\hline \multirow[t]{2}{*}{ Age (Years) } & $\leq 60$ & 83 & 58.9 & 111 & 57.5 & 0.061 & 0.805 \\
\hline & $\geq 61$ & 58 & 41.1 & 82 & 42.5 & & \\
\hline \multirow[t]{2}{*}{ Body mass index } & Normal & 73 & 51.8 & 130 & 67.4 & 8.301 & 0.004 \\
\hline & Abnormal & 68 & 48.2 & 63 & 32.6 & & \\
\hline \multirow[t]{3}{*}{ Education level } & Primary school or below & 30 & 21.3 & 35 & 18.2 & 1.589 & 0.452 \\
\hline & High school & 78 & 55.3 & 120 & 62.1 & & \\
\hline & University or above & 33 & 23.4 & 38 & 19.7 & & \\
\hline \multirow[t]{2}{*}{ Marital status } & Married & 135 & 95.7 & 191 & 99.0 & 3.611 & 0.057 \\
\hline & Single & 6 & 4.3 & 2 & 1.0 & & \\
\hline \multirow[t]{2}{*}{ Medical costs } & Medical insurance & 60 & 28.4 & 82 & 42.5 & 0.000 & 0.990 \\
\hline & Self-supporting & 81 & 71.6 & 111 & 57.5 & & \\
\hline \multirow[t]{3}{*}{ Residence } & City & 40 & 28.4 & 73 & 37.8 & 3.406 & 0.182 \\
\hline & Village or town & 43 & 30.5 & 48 & 24.9 & & \\
\hline & Unknow & 58 & 41.1 & 72 & 37.3 & & \\
\hline Diuration since dagnosis & $\leq 12$ & 95 & 67.4 & 139 & 72.0 & 0.838 & 0.360 \\
\hline (Months) & $\geq 13$ & 46 & 32.6 & 54 & 28.0 & & \\
\hline \multirow[t]{2}{*}{ Stage of cancer } & प & 119 & 84.4 & 172 & 89.1 & 1.620 & 0.203 \\
\hline & Other & 22 & 15.6 & 21 & 10.9 & & \\
\hline Other accompanying & No & 106 & 75.2 & 146 & 75.6 & 0.010 & 0.921 \\
\hline diseases & Yes & 35 & 24.8 & 47 & 24.4 & & \\
\hline
\end{tabular}

Figures 


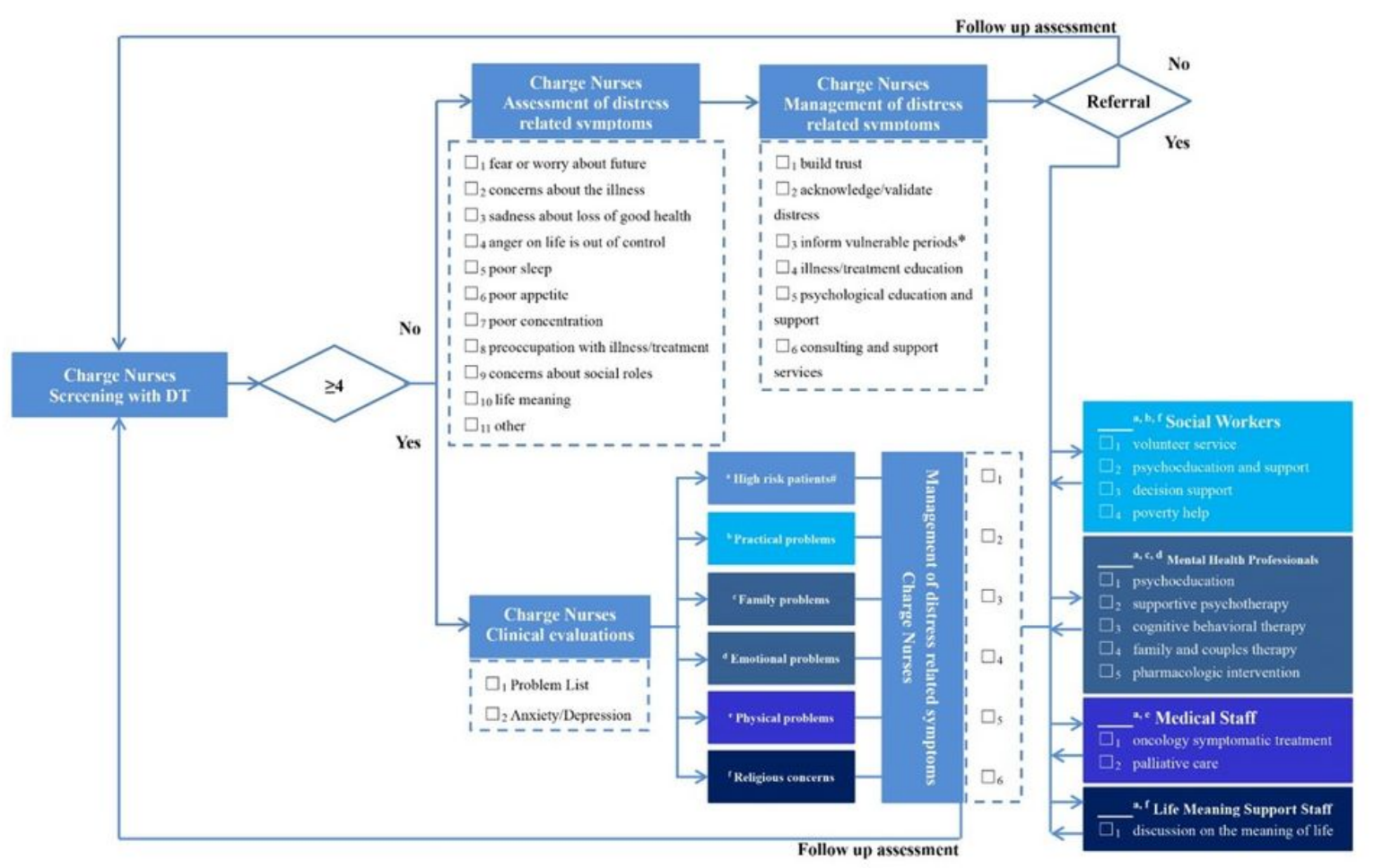

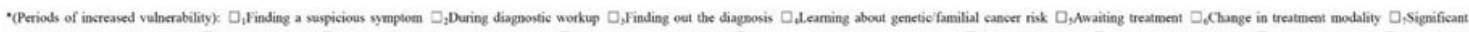

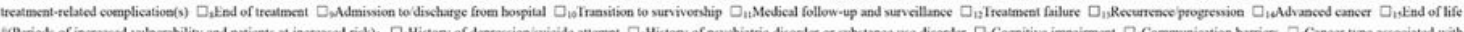

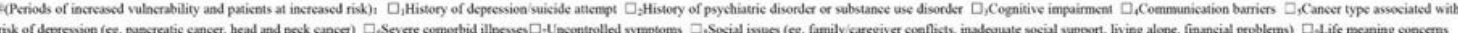

\section{Figure 1}

The distress management clinical pathways 


\begin{tabular}{|c|c|c|c|}
\hline Aspect & \multicolumn{2}{|c|}{ Barriers and Supports } & \multirow[b]{2}{*}{$\begin{array}{l}\text { Solutions } \\
\text { 1. Adding low-level nurses to the nursing team for the distress } \\
\text { management in cancer patients. } \\
\text { 2. Restricting study subjects to gastric cancer patients with } \\
\text { chemotherapy who have been hospitalized for more than } 24 \text { hours. } \\
\text { 3. Integrating the distress management of cancer patients into the } \\
\text { quality control routine of the research site, and being supervised by the } \\
\text { quality control nurses. }\end{array}$} \\
\hline Guidelines & $\begin{array}{l}\text { Barriers 1 } \\
\text { Supports 1, } 2\end{array}$ & $\begin{array}{l}\text { 1. The guidelines implementation increased the workload of nurses. } \\
\text { 1. Hospital decision makers, managers, practitioners, etc. understood } \\
\text { and supported the evidence-based practice of distress management in } \\
\text { cancer patients. } \\
\text { 2. At present, there were sufficient nurses at the research site. }\end{array}$ & \\
\hline \multirow[t]{4}{*}{ Adopters } & Supports 3,4 & $\begin{array}{l}\text { 2. Nurses need to further improve their knowledge, attitudes and } \\
\text { skills related to distress management. } \\
\text { 3. The Distress Management Guidelines in Cancer Patients } \\
\text { were endorsed at the research site. } \\
\text { 4. Routine training sessions of distress management for cancer } \\
\text { patients were accepted by the nurses at the research site. }\end{array}$ & $\begin{array}{l}\text { 4. Training Manual of Distress Management was written based on the } \\
\text { Distress Management Guidelines in Cancer Patients, and } \\
\text { providing the best evidence guidance for professionals, especially } \\
\text { nurses. } \\
5 \text {. Routine training sessions were held for nurses, which increased } \\
\text { knowledge, changed attitudes, improved skills of distress management. }\end{array}$ \\
\hline & $\begin{array}{l}\text { Barriers } 3 \\
\text { Supports } 3,5\end{array}$ & $\begin{array}{l}\text { 3. Communication and cooperation among healthcare professionals } \\
\text { of distress management needs to be further strengthened. } \\
\text { 3. The Distress Management Guidelines in Cancer Patients } \\
\text { were endorsed at the research site. } \\
5 \text {. Routine working group meetings for the guidelines } \\
\text { implementation were accepted by the healtheare professionals. }\end{array}$ & $\begin{array}{l}\text { 4. Training Manual of Distress Management was written based on the } \\
\text { Distress Management Guidelines in Cancer Patients, and } \\
\text { providing the best evidence guidance for professionals, especially } \\
\text { nurses. } \\
\text { 6. Routine working group meetings were held for professionals, which } \\
\text { determined the specific division, referral process, etc. of distress } \\
\text { management. }\end{array}$ \\
\hline & $\begin{array}{l}\text { Barriers } 4 \\
\text { Supports } 3,6\end{array}$ & $\begin{array}{l}\text { 4. Cancer patients had stigma over distress. } \\
\text { 3. The Distress Management Guidelines in Cancer Patients } \\
\text { were endorsed at the research site. } \\
\text { 6. Health education of distress management were provided to cancer } \\
\text { patients and their caregivers. }\end{array}$ & $\begin{array}{l}\text { 7. Education Handbook of Distress Management was written based } \\
\text { on the Distress Management Guidelines in Cancer Patients, } \\
\text { and health education was provided to cancer patients and their } \\
\text { caregivers by nurses. }\end{array}$ \\
\hline & Supports 1 & $\begin{array}{l}\text { 5. Hospital decision makers, managers, practitioners, etc. had little } \\
\text { understanding of distress management in cancer patients. } \\
\text { 1. Hospital decision makers, managers, practitioners, etc. understood } \\
\text { and supported the evidence-based practice of distress management in } \\
\text { cancer patients. }\end{array}$ & $\begin{array}{l}\text { 8. The Distress Management Guidelines in Cancer Patients } \\
\text { were sent to hospital decision makers, managers, practitioners, etc. } \\
\text { with the presentation and explanation from the researchers. }\end{array}$ \\
\hline $\begin{array}{l}\text { Practice } \\
\text { Environment }\end{array}$ & Supports 1,3 & $\begin{array}{l}\text { 6. There was no formal standards, processes, assessment records, } \\
\text { multidisciplinary panels, training and manual for healthcare } \\
\text { professionals, education and handbook for patients and their caregivers } \\
\text { of distress management on institutional level, as well as the distress } \\
\text { management record. } \\
\text { 1. Hospital decision makers, managers, practitioners, etc. understood } \\
\text { and supported the evidence-based practice of distress management in } \\
\text { cancer patients. } \\
\text { 3. The Distress Management Guidelines in Cancer Patients } \\
\text { were endorsed at the research site. }\end{array}$ & $\begin{array}{l}\text { 9. Hospital decision makers, managers, practitioners, etc. were } \\
\text { invited as members of the guidelines implementation panel. } \\
\text { 10. Formal standards, processes, assessment records, } \\
\text { multidisciplinary panels, training and manual for healthcare } \\
\text { professionals, education and handbook for patients and their } \\
\text { caregivers of distress management on institutional level were } \\
\text { developed and endorsed based on the Distress Management } \\
\text { Guidelines in Cancer Patients, as well as the distress } \\
\text { management record. }\end{array}$ \\
\hline
\end{tabular}

\section{Figure 2}

The barriers, supports and solutions of guidelines implementation 